DOI: 10.20472/IAC.2017.33.005

HAO CHANG

National Taiwan Normal University, Taiwan

YU-HUA CHRISTINE SUN

National Taiwan Normal University, Taiwan

\title{
THE EFFECTS OF VISUAL INFORMATION ON BAKING COURSE ADVERTISEMENTS - AN EMPIRICAL STUDY OF TAIWAN
}

\begin{abstract}
:
Purpose - The purpose of this research is to investigate the influence of visual information such as a baking product photo vs a product in action photo on consumers' perceived value and purchase intention.

Design/methodology/approach - This between-subjects design experiment tested the effects of visual information in baking course advertisements and the mediating role of consumers' perceived value. A questionnaire providing a baking course advertisement was implemented to collect responses from the participants.

Findings - This research shows that visual information plays a significant role in baking course advertisements. The results indicated a baking product photo was more persuasive than a product in action photo on consumers' purchase intention. The relationship between visual information and purchase intention is fully mediated by consumers' perceived value.

Originality/value - Advertisement effect has been an issue of great concern to marketers. Therefore, designing a message that can enhance consumers' perceived value and purchase intention is an important task. According to the results above, we suggest marketers use a baking product photo that not only enhance the effect of advertisements, but also increase consumers' perceived value and purchase intention.
\end{abstract}

\section{Keywords:}

Visual information, Advertisement Effect, Perceived Value, Purchase Intention 